
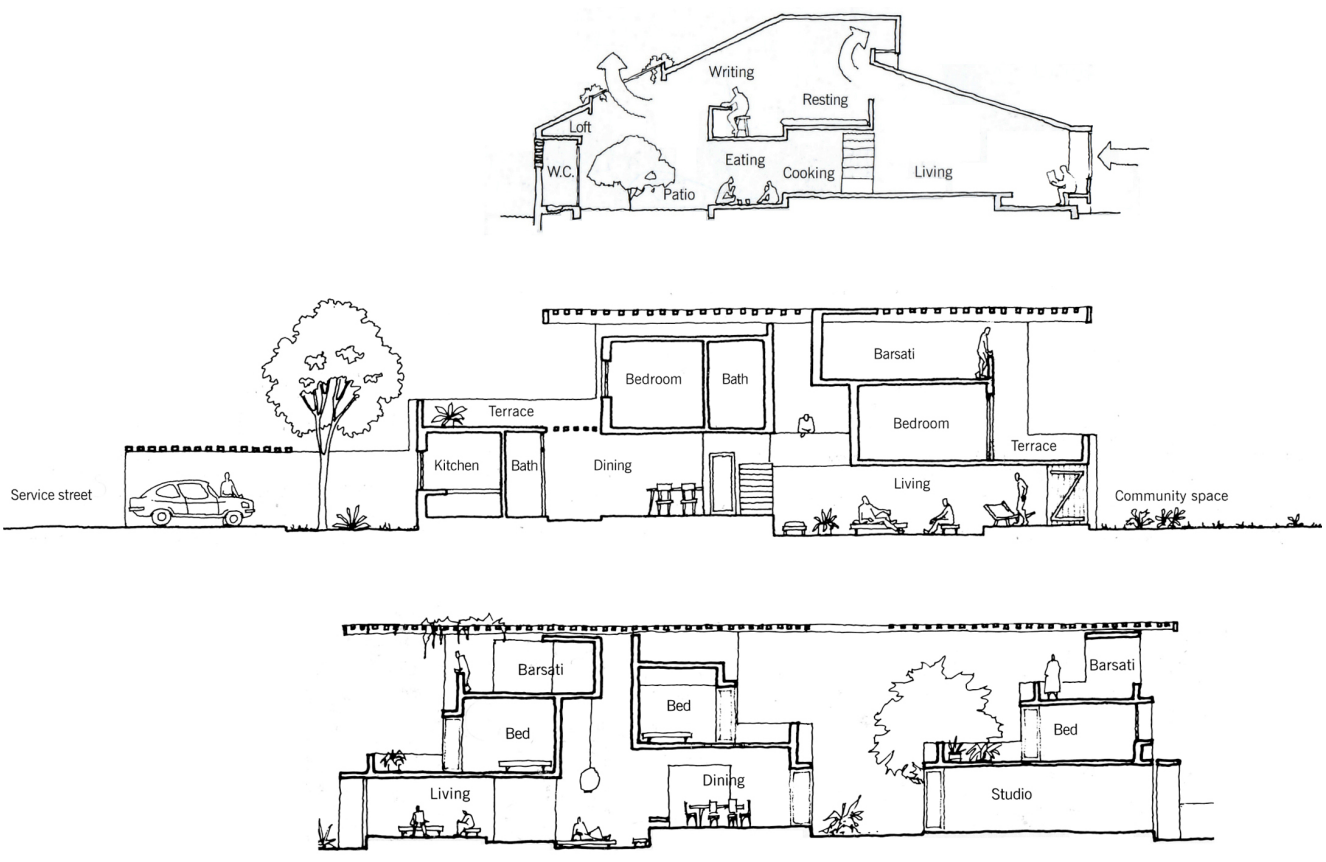

$\wedge \quad F \mid G .1$. Charles Correa. Casa tube en Ahmedabad (1961-1962); Casa tipo en Cablenagar (1967) y Casa Correa en Ahmedabad (1968). Fuente: Charles Correa: Housing and urbanisation. London y New York: Thames \& Hudson, 2000. p. 10, 17, 20.

\section{Charles Correa: transformaciones}

\section{Jaime J. Ferrer Forés}

Recibido 2016.04.03 ::: Aceptado 2016.04.10 DOI: 10.5821/palimpsesto.15.4764$$
\text { ste artículo analiza las constantes y las }
$$
transformaciones de las estructuras profundas del pasado como base de proyecto del maestro (1930-2015) y recorre una trayectoria que fluye desde el compromiso ético y estético de la modernidad a los fundamentos materiales, intelectuales y sagrados de su país. Charles Correa inicia su formación de la Universidad de Bombay y completa los estudios en la Universidad de Michigan (1949-1953) y en el MIT (1953-1955).

Establece su estudio en Bombay en 1958 y construye una obra moderna enraizada en la tradición y el paisaje cultural de la India. La obra de Correa, reconocida con la Medalla de Oro del RIBA en 1984 y el Praemium Imperial en 1998, trata de aunar los preceptos de la modernidad con las tradiciones constructivas de su propio país, ahondando en los fundamentos materiales, intelectuales y sagrados de un conocimiento milenario. En sus obras impregnadas de resonancias y referencias culturales, conjuga el imaginario cultural con referencias a la cosmografía hindú a través de los mandalas e interpretaciones de la civilización india.

\section{Sensibilidad ambiental}

Su dilatada trayectoria profesional se inicia con el museo conmemorativo dedicado a uno de sus héroes, Mahatma Gandhi en Ahmedabad (1958-1963) organizado en torno a un sistema de pabellones, patios que actúan como filtros entre el exterior y el interior y láminas de agua que conformó la sensibilidad ambiental del arquitecto². La ventilación natural y los sistemas pasivos de adaptación climática que introduce en el Memorial Gandhi se desarrollarán en los proyectos domésticos de la década de los 60 y 70. En la casa tube en Ahmedabad (1961-1962), plantea un prototipo de casa desarrollada en una única crujía de 3,5 m organizada en torno a un patio interior pergolado que protege la casa de la radicación solar propicia la convección del aire y la ventilación cruzada mediante una sección caracterizada por las cubiertas inclinadas y cuyo modelo ampliará en la casa Ramkrishna (1962-1964) destinada a una familia acomodada.

En el proyecto del conjunto de viviendas Cablenagar (1967), Charles Correa formulará una serie de principios de adaptación climática que introducirá en sus obras, precursoras de los actuales sistemas de ahorro energético y que proceden del legado de la tradición y de la capacidad de adaptación de las sociedades tradicionales.
Adaptándose a las exigencias climáticas de un clima cálido y seco, los modelos planteados se extienden en una crujía de 3,3 m. y tratan de responder al clima con medios escasos: introduciendo patios y cubiertas estratificadas con pérgolas que eviten la incidencia directa del sol en la cubierta y con un volumen interior de la casa que favorezca la ventilación cruzada y la convección del aire. Con estos principios construirá la Casa Parekh en Ahmedabad (1967-1968) ordenada en tres cruijas que alternan secciones climáticas en forma piramidal para el verano, cerrándose al exterior y abriéndose al interior y en invierno en forma de pirámide invertida extendiéndose hacia las terrazas con pérgolas. En la casa Correa en Ahmedabad (1968) organiza las secciones climáticas longitudinalmente y establece una concatenación espacial de los ámbitos domésticos (FIG 1).

La reflexión sobre las exigencias medioambientales, la adecuada orientación al sol y a los vientos, la ventilación natural, la protección solar y la cubierta estratificada que contribuye a disipar el calor que anticipa en sus proyectos domésticos se trasladará a todas las escalas, como en el edificio de oficinas Ecil en Hyderabad (19651968), ilustrando la conciencia medioambiental del arquitecto.

En el conjunto de viviendas GHB-2 en Ahmedabad (1961) amplía la valencia espacial de la casa tube con la alternancia de la dimensión de la crujia y la introducción de patios, y compone un sistemático tapiz de crujías y patios que anticipa el conjunto de viviendas PREVI en Lima (1967-1973) donde plantea un modelo de baja altura y alta densidad con una vivienda crecedera a partir de una unidad básica. Los cambiantes raíles desmontables de las maquetas de trenes eléctricos de su infancia, que determinaron su temprana vocación por la arquitectura, modelan el universo espacial del arquitecto mediante el sistema de crujías de muros equidistantes con el que desarrollará los proyectos domésticos ${ }^{3}$.

En el proyecto para el conjunto de viviendas Punjab en Bombay (1966-1967) Charles Correa desarrolla la noción del Raumplan loosiano y organiza la casa mediante un sistema de medias alturas que permite interconectar los espacios de la casa en distintos niveles. Este carácter tridimensional de la vivienda introduce una importante cualidad espacial y ratifica la apreciación del arquitecto danés Jørn Utzon cuando afirma que en occidente nos atraen los muros, así como en el oriente nos atraen los suelos. Correa establece una composición dinámica en sección, un Raumplan que proporciona un movimiento espacial y la oportuna adecuación funcional de los espacios aprovechando la variación de alturas y desarrolla este sistema de agrupación espacial en la torre de viviendas Sonmarg en Bombay (1961-1966), caracterizada por unas fachadas de una característica profundidad que enriquecen los límites del espacio doméstico, o en la torre Kanchanjunga en Bombay (1970-1983) con el escalonamiento de los apartamentos en distintos niveles que favorece la interconexión espacial entre los ámbitos domésticos y genera un contínuum hacia la terraza jardín a doble altura ${ }^{4}$ (FIG 2).

En estos proyectos de vivienda colectiva se ilustra la investigación compositiva, tipológica y tecnológica que caracterizará la obra de Correa donde ensaya los planteamientos formales y compositivos propios de la modernidad adaptados al contexto introduciendo dispositivos de control ambiental. Para Correa, "en un país pobre como la India, sencillamente no nos podemos permitir derrochar recursos para instalar una torre de cristal con aire acondicionado bajo un sol abrasador. $Y$ esto es una ventaja. Significa que el propio edificio, con su forma, debe crear el confort que necesita el usuario".

Para Charles Correa, el genius loci debe anteponer el clima y la cultura a la forma. En la India, las marcadas condiciones medioambientales de un clima cálido, han determinado en la arquitectura de Charles Correa la apropiación de los recursos de la tradición y la reinterpretación de las estrategias de la construcción vernácula: desde las organizaciones urbanas compactas a los patrones de las sociedades tradicionales, con los patios ajardinados, los estanques, las celosías, las pérgolas y porches, los lugares intermedios y los umbrales que median entre la naturaleza y el espacio construido. Para Correa, "esta variedad de espacios abiertos proporcionan el entorno más placentero y más apropiado para nuestras actividades". 6

\section{Itinerarios. "The ritualistic pathway"}

Para Correa, además, el clima incide en la percepción de la forma arquitectónica. ${ }^{7}$ Los modos intemporales y la sabiduría climática de la construcción vernácula determinan los espacios intermedios "entre la caja cerrada y el espacio abierto al cielo, un contínuum de zonas con diversas definiciones y grados de protección". ${ }^{8}$

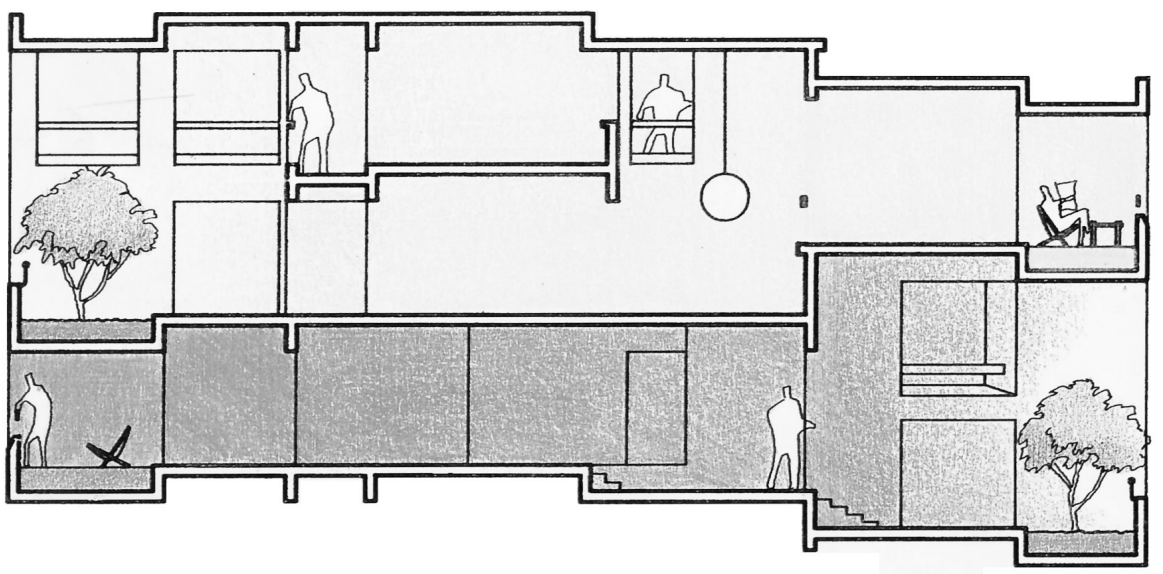


Esta concatenación de arquitecturas de conexión en términos de Louis Kahn y la transición gradual entre ellos caracteriza la forma arquitectónica en un clima cálido. Correa señala que "las sutiles modulaciones de la luz y de la calidad del aire ambiental registran cada transición de nuestros sentidos."

Los templos hindúes son experimentados como un itinerario que discurre entre los espacios sagrados. Para Correa, "este movimiento procesional al aire libre es de suma importancia religiosa y simbólica. Lo encontramos en todas la regiones cálidas de la tierra, desde los templos del Sol de México -que constan de pirámides y, más importante, de los sagrados espacios abiertos que éstas definen- hasta los templos de Bali -con sus caminos rituales que ascienden por las laderas-. Las ceremonias religiosas de Asia han enfatizado siempre este movimiento a través de espacios abiertos al cielo, así como las sensaciones casi místicas que provocan en nosotros." 10

En la reflexión de Correa confluyen los análisis espaciales de Rex D. Martienssen de la arquitectura griega con el estudio de los propileos, el espacio de transición, el enmarque visual y la percepción gradual en el acercamiento a un templo dórico, con la memorable narración de la promenade architecturale de Le Corbusier. ${ }^{11}$ La noción de este itinerario, "a ritualistic pathway along a shifting axis" lo desarrollará en su primera obra, el pabellón temporal Handloom en Delhi (1958). ${ }^{12}$ Correa establece un recinto delimitado por un muro de adobe que acoge los distintos ámbitos expositivos inscritos en una retícula modular de $7 \times 7$ $\mathrm{m}$ y organiza un itinerario secuencial, mediante rampas y escaleras, a distintos niveles en torno a un patio. Sobre este modulado podio procesional se erigen quince estructuras chatri, un elemento base con forma de pirámide invertida con un único apoyo central y atirantado con tensores metálicos y cuyos revestimientos
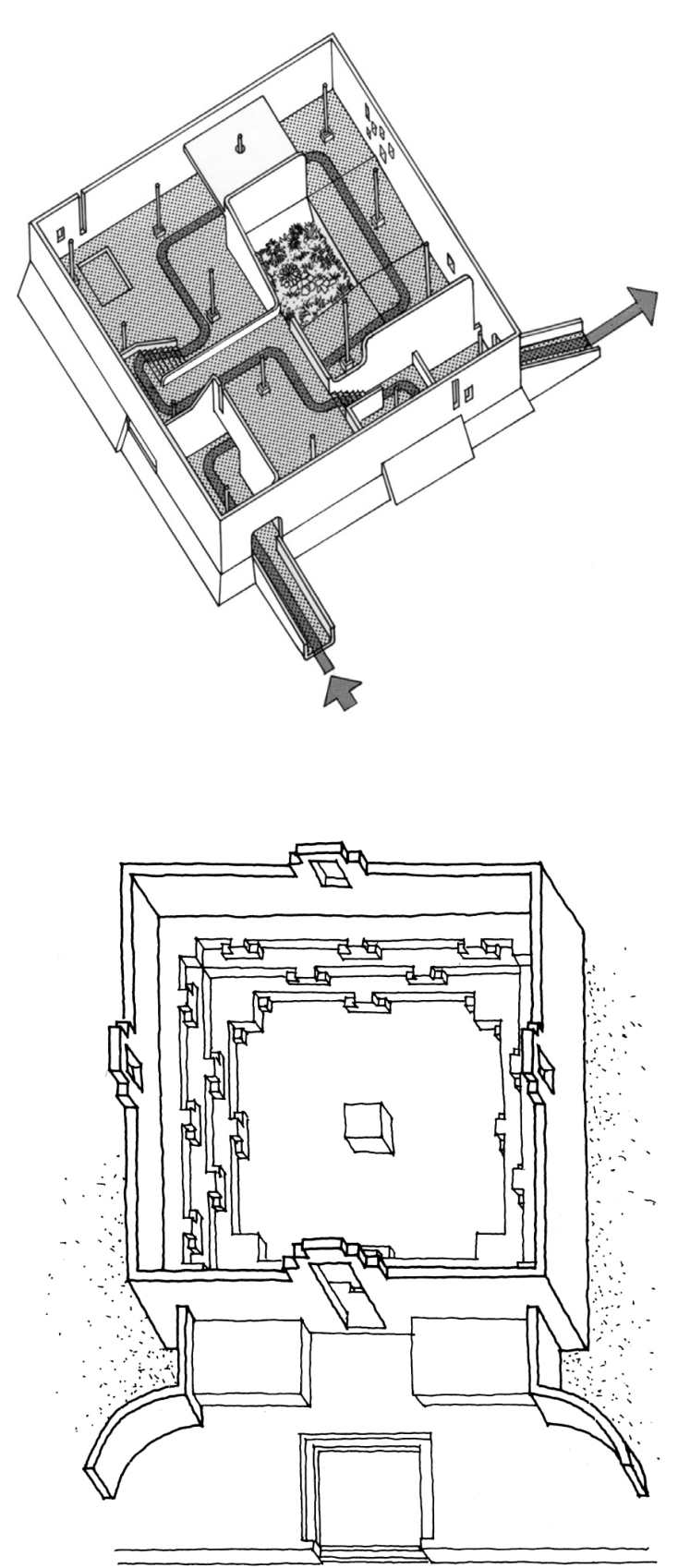

^ 1 FIG. 3. Charles Correa. Pabellón Handloom en Delhi (1958) Fuente: KHAN, Hasan-Uddin. Charles Correa. Singapore:
Concept Media, 1987. p. 27.

$\wedge$ FIG. 4. Charles Correa. Surya Kund en Delhi (1986). Fuente: FRAMPTON, Kenneth y CORREA, Charles: Charles Correa,

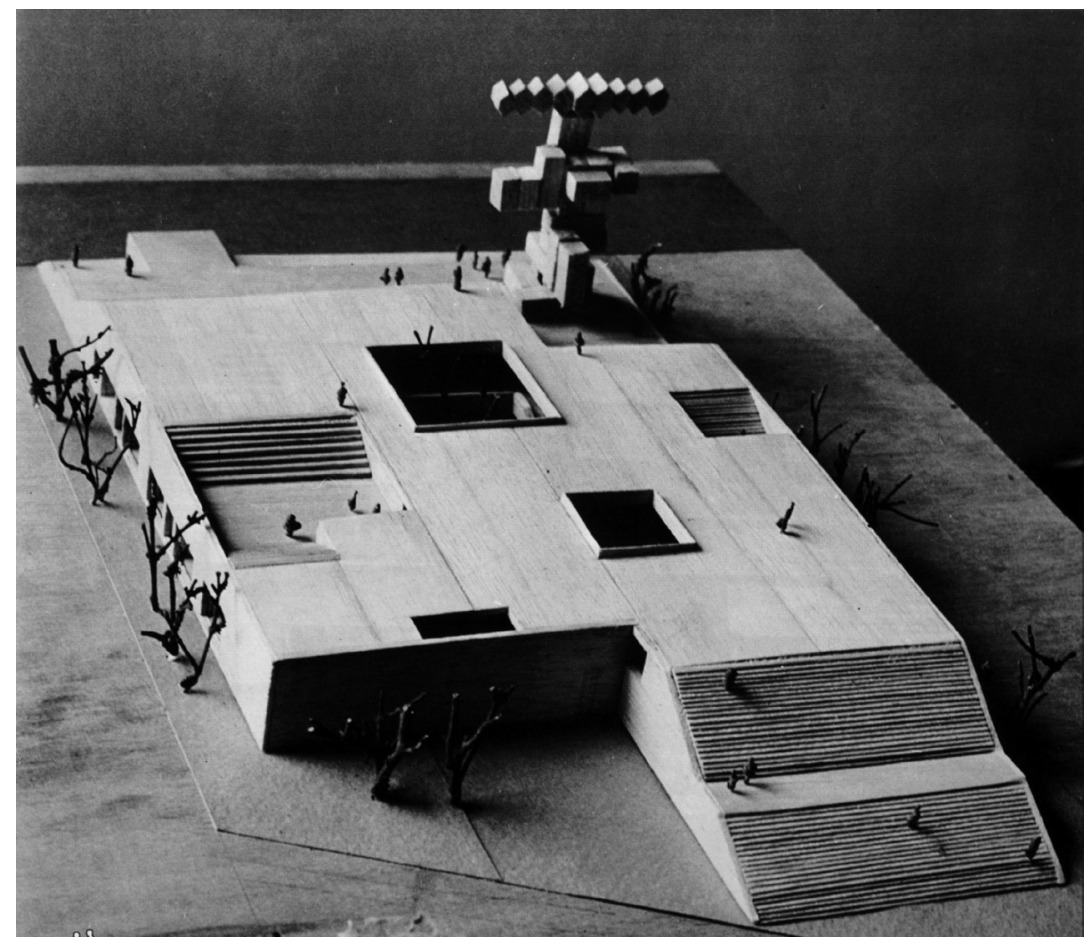

FIG. 5. Charles Correa. Maqueta del Proyecto para el pabellón de la India en la exposición de Osaka en Japón (1969). Fuente: CANTACUZINO, Sherban. Charles Correa.

textiles que filtran la luz evocan las shamianas, las tradicionales tiendas ceremoniales y festivas (FIG 3).

Este recorrido en espiral ascendente y descendente concebido en el pabellón Handloom se desarrollará posteriormente en el pabellón Hindustan Lever en Delhi (1061) cuyas supeficies plegadas dehon que envuelven los espacios interiores, y generan una continuidad entre suelo y techo, enriquecen la secuencia perceptiva mediante la compresión y dilatación del espacio y canalizan el flujo del público. Para subrayar su vocación de paisaje interior, el itinerario transita a distintos niveles mediante rampas, escaleras, plataformas e incorpora láminas de agua y una serie de lucernarios que propician la ventilación natural y tratan de mejorar las condiciones ambientales del singular volumen poliédrico.

Recintos y plataformas. Los espacios abiertos al cielo

En su exploración arquitectónica Charles Correa desarrolla la noción del itinerario que vertebra la organización espacial del proyecto y en su búsqueda de constantes, invariantes o patrones recurre a los elementos esenciales de la construcción vernácula: los recintos y las plataformas.

Fuera del ámbito doméstico, Correa explora las posibilidades del muro que ensaya en su obra residencial. Con el proyecto del Surya Kund en Delhi (1986) evoca los tradicionales kunds, aljibes escalonados que forman parte del ritual de purificación previo al ingreso a los templos, y establece un elemental recinto delimitado por un muro que acoge un foro de debate y reinterpreta en su interior las escalinatas tradicionales de los kunds que actúan como gradas de los espectadores (FIG 4). En el centro Jawahar Kala Kendra en Jaipur (19861992) reinterpreta el navgraha, el mandala de nueve cuadrados mediante la construcción de nueve recintos interconectados y delimitados por un muro de piedra roja de Agra. En el complejo Vidhan Bhavan en Bhopal (1980-1996), que alberga la Asamblea del Gobierno de Madhya Pradesh, define un rotundo recinto circular que como una fortaleza reinterpreta las cosmologías budistas del cercano templo circular Stupa en Sanchi, y contrasta con la organización ortogonal del interior donde traza los itinerarios en torno a los patios.

El recinto constituye un mecanismo elemental para fundar un lugar y complementariamente una plataforma define un plano horizontal y prepara un suelo para implantar una construcción sobre él. Así, la edificación incorpora un estrato geográfico más al territorio, desde los tres escalones de la crepidoma del templo dórico a las escalinatas monumentales de las arquitecturas de la Antigüedad, la secuencia de suelos concatenados produce un recorrido secuencial que subraya la percepción dinámica de la organización espacial y enfatiza la noción de expectativa y culminación.

Para el arquitecto danés Jørn Utzon las plataformas constituyen "un formidable concepto arquitectónico" y en su artículo titulado Plataformas y mesetas publicado en 1962 se refiere a las plataformas "en la India y en
Oriente, sin olvidar las acrópolis y el Medio Oriente, muchas plataformas maravillosas de diferentes tipos constituyen la base de composiciones arquitectónicas magníficamente concebidas. Una de las más destacadas es la gran mezquita de Old-Delhi."13 Sobre la plataforma añade "se experimenta una profunda sensación de lejanía y de paz". ${ }^{14}$ Para Utzon la plataforma nos separa progresivamente del entorno inmediato, de la densa selva en la península del Yucatán o del denso tráfico de las ciudades y nos relaciona con una nueva dimensión: "desde arriba no se ve otra cosa que el cielo y las nubes que pasan: un nuevo planeta." Así la plataforma pertenece a la escala territorial y trata de recuperar el vínculo profundo que relaciona la naturaleza y la arquitectura.

Con la ambición de relacionar la arquitectura con e medio, Correa explora el potencial de la plataforma en un conjunto de obras que fluyen desde los hallazgos formales de las plataformas concatenadas y de los itinerarios procesionales del Kasturba Gandhi Samadhi (1962-1965) o del Gandhi Darshan en Rajghat (19681969) subrayando su condición esteorotómica de pertenencia a la tierra, a la estratificación horizontal del Pabellón de la India en la exposición de Osaka, Japón (1969), cuyas partes, servidas y servidoras, aluden a los criterios kahnianos; o las plataformas talladas con patios del Bharat Bhavan en Bhopal (1975-1981) y del Museo Nacional de Artesanía en Delhi (1975-1990).

El conjunto del memorial Kasturba Gandhi Samadhi en Pune (1962-1965) establece una idea de circulación de carácter procesional confinado entre muros que culminan en el samadhi y una rampa caracterizada por el solemne y lento ascenso a la plataforma que origina un atractivo anfiteatro al paisaje. El samadhi contiene las cenizas de la esposa de Mahatma Gandhi, fallecida en 1944 cuando estaban tanto ella como Gandhi bajo arresto domiciliario. La plataforma se corresponde con una arquitectura que potencia el carácter del paisaje en los jardines del Palacio de Aga Khan en Pune, en un diálogo con la propia geografía y tradición cultural. En el basamento de la plataforma se aloja un pequeño museo dedicado a Kasturba Gandhi.

Frente a la condición narrativa de los memoriales, Charles Correa recurre a la naturaleza profundamente abstracta del proyecto y construye un itinerario que denomina "ritualistic pathway along a shifting axis". La secuencia de exteriores y de interiores que se suceden en la arquitectura de la Antiguëdad inspiró un itinerario serpenteante a través de la concatenación de espacios vinculados al entorno y donde las escaleras tangenciales que enfatizan el dinamismo de las circulaciones se contraponen a los bancos que señalan los ámbitos de estancia sobre la plataforma.

En el proyecto para el pabellón de la India en la exposición de Osaka en Japón (1969), Correa recurre a arquetipos de la tradición como la plataforma escalonada evocando los ghats, las escalinatas que descienden hasta los ríos sagrados, y propone una estructura principal formada por grandes plataformas colectivas que mediante amplias y solemnes escalinatas conducen al público hacia el interior de la plataforma donde se modelan los itinerarios y se acoge el programa expositivo en torno a los patios. 


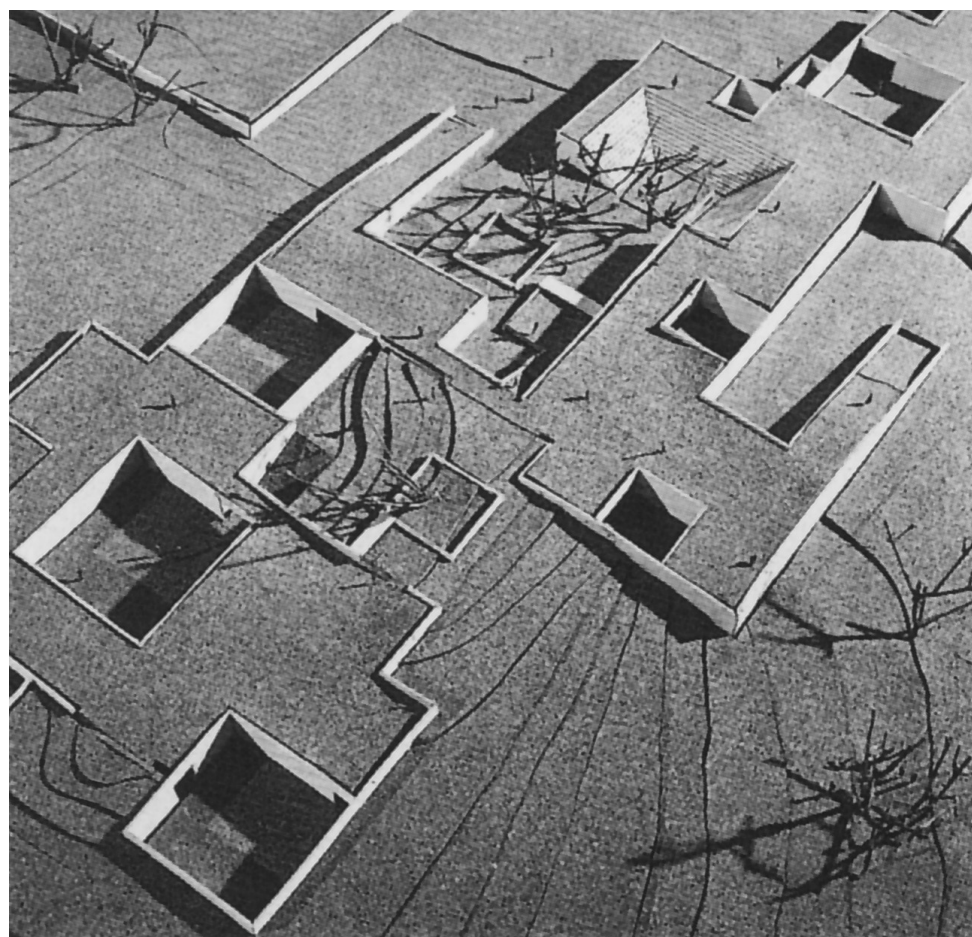

1 FIG. 6. Charles Correa. Gandhi Darshan en Delhi (1968-1969). Fuente: FRAMPTON Kenneth y CORREA, Charles: Charles Correa, Nueva York: Thames \& Hudson,

Correa explica mediante la fuerte expresividad de la maqueta la rotundidad de la propuesta como derivada de la Antigüedad, tan esencial y con una orientación fuertemente dinámica que propicia una secuencia diversificada de itinerarios (FIG 5). Los ecos formales de las plataformas evocan también las arquitecturas precolombinas que habían suscitado el interés en los arquitectos orgánicos. El gran volumen escultórico de la figura mitológica de Ravana con sus múltiples cabezas se yergue sobre el conjunto y establece el contrapunto vertical de las dilatadas plataformas, acentuando además su dimensión ancestral y rotunda del pabellón. En el pabellón de Brasil en Osaka, Paulo Mendes da Rocha modela y excava igualmente un suelo activado que define el territorio de la arquitectura. El suelo transformado no sólo prepara el enclave del edificio en el terreno, sino que constituye el soporte activo de la arquitectura y establece un singular espacio de convivencia.

Concebido como una composición paisajística y vinculado a una área de espacios verdes en Rajghat, el conjunto Gandhi Darshan en Delhi (1968-1969) se organiza en torno a un sistema de patios y proyecta una secuencia ininterrumpida que desarrolla la noción del "ritualistic pathway along a shifting axis". Desdibujando su presencia y enterrándose parcialmente, el acceso a través de un profundo pasaje entre muros paralelos es indirecto y se extiende en un sistema de patios concatenados. Para Correa el tránsito entre el exterior y el interior, la progresión y el descubrimiento progresivo son decisivos. Los cambios de dirección dilatan la experiencia y constituyen un experiencia perceptiva intensa que enriquece las cualidades sensoriales de los visitantes.

Los diferentes usos del programa que conmemoran las enseñanzas de Mahatma Gandhi están articulados en torno a una secuencia de patios y espacios cubiertos. El suelo y los planos horizontales de la plataforma son tallados en terrazas que se presentan continuas y matizadamente discontinuas, minimizando su presenci en el entorno y evocando los anfiteatros clásicos y las arquitecturas de la Antigüedad (FIG. 6).

Enfatizando la continuidad espacial mediante los accesos, los jardines y la implantación en el paisaje, la configuración de espacios llenos y vacíos que ensaya en el conjunto conmemorativo se extiende en los proyectos del Bharat Bhavan en Bhopal (1975-1981) y en el Museo Nacional de Artesanía en Delhi (1975-1990).

Una plataforma horizontal es el argumento generador del Centro de Arte Bharat Bhavan en Bhopal (19751981) y el itinerario secuencial es el soporte espacial que vertebra al conjunto a través de una sucesión de espacios conectados con el exterior. El edificio está caracterizado por una gran plataforma que asume el desnivel topográfico y se prolonga con rotundidad con los acentos plásticos de los lucernarios troncocónicos.

El plano horizontal de la plataforma se convierte en un espacio colectivo y queda pautado por una serie de patios que albergan la entrada y las zonas comunes de las áreas expositivas que actúan como lugares de encuentro y culminan en un anfiteatro entallado en la plataforma que se abre al paisaje del lago.
Charles Correa se inspira en los tipos edificatorios tradicionales y en los espacios urbanos de la India que se convierten en un modelo para la composición del Museo Nacional de Artesanía en Delhi (1975-1990). El resultado de estas influencias es una pieza cualificada por patios y jardines, arraigada en el contexto y que introduce las estrategias medioambientales ensayadas en su arquitectura doméstica para combatir el rigor del clima local. Correa plantea un cuerpo de baja altura perforado por patios que manifiesta los ecos de las plataformas de la Antigüedad y culmina el recorrido procesional con el anfiteatro entallado en la plataforma. Una secuencia diagonal de tres patios articulados entre sí ordena el conjunto y establece una suma de salas encadenadas que se suceden entre los distintos patios y muestras artesanales y dibujan un edificio de perímetro irregular y quebrado. Para Correa "a continuous pedestrian spine running throught the heart of the museum- a metaphor for the Indian street[...]". ${ }^{15}$ El intrincado itinerario conjuga las diversidades culturales de la India con las tradiciones locales y las técnicas artesanales.

\section{Conclusión}

Con la ambición de expresar la esencia del imaginario cultural a través del lenguaje y la técnica moderna, Charles Correa interpreta la modernidad desde su contexto material, climático y simbólico y construye una arquitectura ejemplar en su adecuación climática, compromiso social y legado cultural.

Para relacionarse cuidadosamente con el contexto y la cultura, Correa tomó conciencia de la especificidad de construir en un clima cálido y seco, estudiando la cultura constructiva y la capacidad de adaptación de las sociedades tradicionales ante estas rigurosas y adversas condiciones climáticas, analizando cómo se organizan en torno a los espacios intermedios que denomina "open to sky space" y cómo se establecen sus relaciones sociales y se vertebran los itinerarios procesionales. Estas reflexiones le llevaron a considerar los factores climáticos, los cambios estacionales y las condiciones específicas de los emplazamientos y a introducir los sistemas pasivos que dotan de confort a los usuarios en su arquitectura. Todos estos precursores principios ambientales, que se condensan en el principio "form follows climate", guiaron la obra de Charles Correa.

Comprometido por la dimensión social de la arquitectura, para Correa la arquitectura es la expresión de un modo de vida más justo y sus convicciones sociales se proyectarán en sus comprometidas propuestas atentas a la realidad cultural, social y económica de la India tratando de combatir la desigualdad y la pobreza y responder a los acuciantes retos urbanos de las grandes ciudades del tercer mundo, el hacinamiento o la pobreza interviniendo en el planeamiento urbano, la construcción de bajo coste y los problemas urbanos.

En el artículo titulado "Raíces y puentes", Correa desvela las claves de su arquitectura y ejemplifica cómo los grandes artistas como Gaughin o Picasso establecen lo que Correa denomina "puentes" entre distintas culturas donde las imágenes no se transfieren sino se transforman. La modernidad del proyecto de Charles Correa se enriquece con las referencias a la gran arquitectura del pasado y este itinerario analítico por sus obras explora cómo los hallazgos formales de las plataformas y los itinerarios procesionales, que aúnan el imaginario cultural de su propio país con los preceptos de la modernidad, se transforman y se incorporan al proyecto moderno mediante la abstracción. Su obra enraizada en el legado de una civilización milenaria pertenece a la gran tradición de la arquitectura no por el empleo de las formas de la arquitectura histórica, sino por su constante transformación. Así, para Correa, "cuando decimos que el arte construye puentes, esto no significa que excluya las raíces. Al contrario, sin raíces no pueden existir los cimientos del puente que se está construyendo." 16

${ }_{1}^{1}$ Para William J. R. Curtis "la mejor arquitectura india de los años 1980 y principios de 1990 también consiguió mantener antiguo, y combinar las respuestas locales conl, lo moderno y lo universales. [...] Siguió desarrollándose en una simbiosis creativa con los poderosos prototipos generados por Le Corbusier y Louis Kahn en las décadas de 1950 y 1960". CURTIS, William R. La arquitectura moderna desde 1900. Londres y Nueva York: Phaidon, 2006. p.649.

2 El Museo conmemorativo Gandhi evoca la obra de Louis Kahn de los Baños de la Comunidad judía en Trenton, New Jersey Doshi, and Correa in Political and Social Context". En: An Architecture of Independence: The Making of Modern South Asia. New York: The Architectural League of New York, 1998. p. 17.

${ }^{3}$ CORREA, Charles. "Trenes eléctricos de la marca Hornby, jardines chinos y arquitectura". En: CORREA, Charles. Un lugar a la sombra. Barcelona: Fundación Caja de Arquitectos, 2008. p.

El escalonamiento lo desarrollara en el Bay Island Hotel en Port Blair (1979-1982) cuya sección escalonada evoca el antecedente historico del palacio Padmanapuram y alude también al proyecto de apartamentos proyectados por Jorn Utzon en Elineberg en erban. Charles Correa. Singapore: Concept Media, 1984. p. 90.

${ }^{5}$ CORREA, Charles. Un lugar a la sombra. Barcelona: Fundación Caja de Arquitectos, 2008. p. 25.

${ }^{6}$ Ibídem. p. 21.

Para Charles Correa, "del clima depende decisivamente nuestra necesidad y percepción de la forma arquitectónica." CORREA, Charles. Un lugar a la sombra. Barcelona: Fundación Caja de

${ }^{8}$ CORREA, Charles. Un lugar a la sombra. Barcelona: Fundación Caja de Arquitectos, 2008. p. 20.

${ }^{9}$ Ibídem. p. 20.

${ }^{0}$ Ibídem. p. 23.

MARTIENSSEN, Rex D. La idea del espacio en la arquitectura griega: con especial referencia al templo dórico y a su
emplazamiento. Buenos Aires: Nueva Visión, 1984.

${ }^{12}$ CORREA, Charles. The ritualistic pathway. 5 projects: a portfolio of architecture by Charles Correa. With essays by Kenneth
Frampton, John Russell, Jyotindra Jain, Gautam Bhatia. 1993.

${ }^{13}$ UTZON, Jørn. "Plataformas y mesetas: ideas de un arquitecto danés". En: FERRER FORÉS, J. J. Jern Utzon. Obras y Proyectos.
Barcelona: Gustavo Gili, 2006. p.144.

${ }^{14}$ Ibídem. p. 144.

${ }^{15}$ CORREA, Charles. "The Blessings of the Sky". En: FRAMPTON, Kenneth y CORREA, Charles: Charles Correa, Nueva York:

Thames \& Hudson, 1997. p. 26

${ }^{16}$ CORREA, Charles. Un lugar a la sombra. Barcelona: Fundación Caja de Arquitectos, 2008. p. 98.

ABSTRACT

El maestro de la arquitectura moderna India, Charles Correa (1930-2015) construye una obra moderna enraizada en la tradición y el paisaje cultural de la India. Su obra evoca el imaginario cultural a través de la abstracción, concilia lo local con lo universal y reivindica la identidad india. La arquitectura de de las estructuras profundas del pasado como base del de las estructuras profundas del pasado como base del proyecto, desde los principios de adaptación climática, que proceden del legado de la tradición y de la capacidad de ada lación de las sociedades tradicionales, a la reinterpretación de los arquelipos espaciales de los antecedentes historicos que denomina "open-to-sky space" y vertebra mediante el itinerario procesional "he rualstic pathway" que enfatiza la percepción del itina del ther a y la nocion de expectativa, que in ensifca la experiencia yspacial medante los propleos, y de culminación a

PALABRAS CLAVE: Charles Correa, transformaciones, clima, recinto, plataforma.

JAIME J. FERRER FORÉS es Doctor Arquitecto y Profesor agregado interino del Departamento de Proyectos Arquitectónicos de la ETSAB Universitat Politècnica de Catalunya (UPC). 